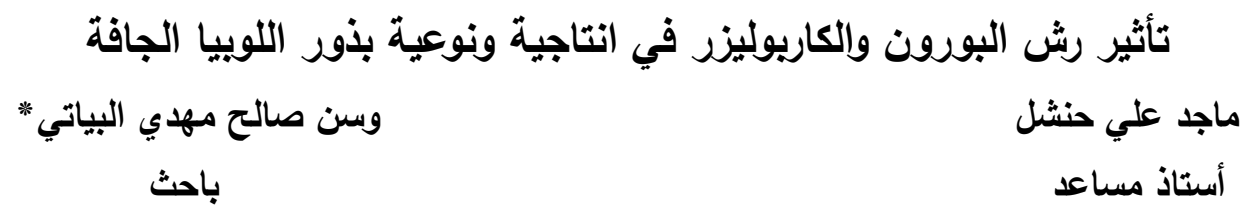

wassan.albayati@yahoo.com

$$
\text { قسم البستنة وهندسة الحدائق - كلية الزراعة -جامعة بغداد }
$$

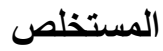

نفذت تجرية حقلية للموسمين الرييعي والصيفي في قسم البستنة وهندسة الحدائق/ كلية الزراعة / جامعة بغداد/ أبوغريب للعام 2014 لاراسة تأثير

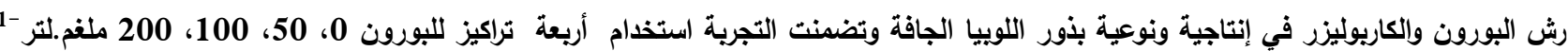

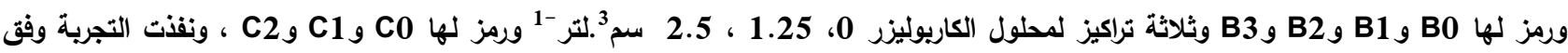
تصميم القطاعات التامة التعشية RCBD ويثلاث مكررات وحلت النتائج باستخدام اقل فرق معنوي L.S.D على مستوى احتمالية 0.05.

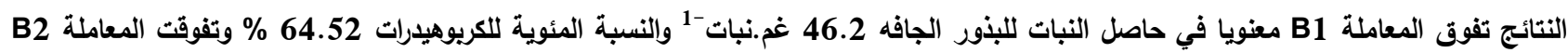
معنويا في الكثافة الظاهرية للبذور 0.669 غم.سم والنسبة المئوية للبروتين في البذور 22.76 م3 في في الموسم الربيعي بينما تفوقت المعاملة

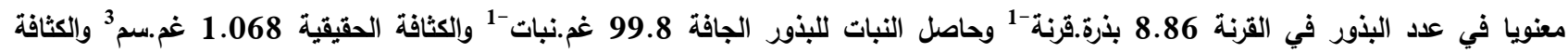

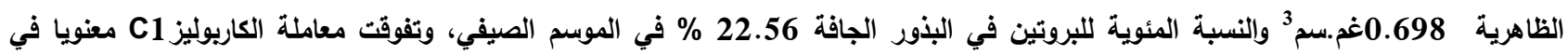

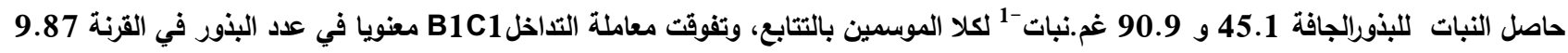
بذرة.قرنة-1 وحاصل النبات للبذور الجافة 59.7 غم.نبات-1 في الموسم الربيعي، بينما تفوقت المعاملة B3C2 معنويا في عدد البذور في القرنة

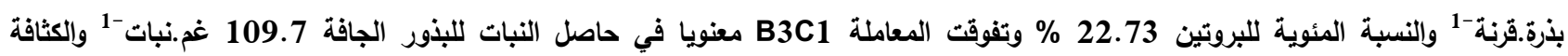
الظاهرية 0.703 غم.سم3 في الموسم الصيفي، في حين تفوقت المعاملة B1C0 معنويا في النسبة المئوية للكريوهيدرات في البذور 64.80 لكلا الموسمين بالتتابع.

\title{
THE EFFECT OF SPRAYING OF BORON AND CARBO LIZER ON THE PRODUCTIVITY AND QUALITY OF DRY COWPEA SEEDS
}

\section{A. Hanshal \\ Assist prof.}

\section{W. S. M. Albayati*}

Researcher

\section{ABSTRACT}

Dept. of Horti. and Landscape Gardening - Coll.of Agric- University of Baghdad

\begin{abstract}
An experiment was carried out at the vegetable fields of Horticulture and Landscaping Design Dep. / College of Agriculture / university of Baghdad / Abu Ghraib on season 2014 to study the effect of spraying boron and Carbo lizer on the productivity and quality of cowpea seeds. Ramshorn c.v. Seeds are sowed on two dates; Spring and summer date. The experiment also includes the use of four concentrations of Boron: $0,50,100$ and $200 \mathrm{mg}^{-1} \mathrm{~L}^{-1}$ Which Symbolized B1,B2,B3 and B4 and three concentrations of Carbo lizer; $0,1.25$ and $2.5 \mathrm{~cm}^{3} \cdot \mathrm{L}^{-1}$ Which Symbolized C1,C2 and C3. The experiment analysis is carried out in accordance to the experimental with in Randomized complete block design (RCBD) and it is adopted in three replacements, and it is compared with L.S.D. at 0.05 probability level. The results showed superiority of treatment $B 1$ in yield of dry seeds 46.2 g.plant $^{-1,}$ percentage of carbohydrates $64.52 \%$ and the treatment $\mathrm{B} 2$ showed a significant increase in the bulk density of the seeds $0.669 \mathrm{g.cm}^{3}$, percentage of protein in the seeds $22.76 \%$ in the spring date while treatment $\mathrm{B3}$ show a significant increase in the number of Seeds in pods 8.86 seed.pod ${ }^{-1}$, yield of dry seeds 99.8 g.plant $^{-1}$, specific density $1.068 \mathrm{g.cm}$, bulk density $0.698 \mathrm{g.cm}$ and percentage of protein in the dry seeds $22: 56 \%$ in the summer date, and excelled treatment of Carbo lizer $\mathrm{C} 1$ show a significant increase in yield of dry seeds $45.1,90.9 \mathrm{~g}^{\text {plant }} \mathrm{t}^{-1}$ for both dates respectivelly, The interaction treatment $\mathrm{B} 1 \mathrm{C} 1$ show a significant increase in the number of seeds in pod $9.87 \mathrm{seed}^{-p o d^{-1}}$ and yield of dry seeds g.plant ${ }^{-1} 59.7$ g.plant $^{-1}$ in the spring date, while the interaction treatment was significantly $\mathrm{B3C2}$ showed a significant increase in the number of seeds in pod 9.27 seed.pod $^{-1}$ and percentage of protein $22.73 \%$ and The interaction treatment $\mathrm{B} 3 \mathrm{C} 1$ show a significant increase yield of dry seeds $109.7 \mathrm{~g} . p l a n t^{-1}$ bulk density $0.703{\mathrm{~g} . \mathrm{cm}^{3}}^{3}$ in the summer date, The interaction treatment B1C0 show a significant increase in percentage of carbohydrates 64.70 and $64.80 \%$ for both dates respectively.
\end{abstract}

Key words: Dry seeds, Bulk density, Carbohydrates.

Part of M.Sc.thesis of second author. 
العضوية التي أصبح من شأنها إمداد النبات بـ يعد احد العوامل المهمة في زيادة نشاط عملية التمثيل

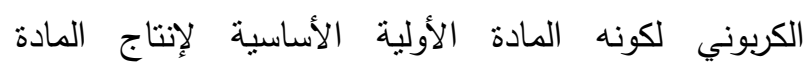

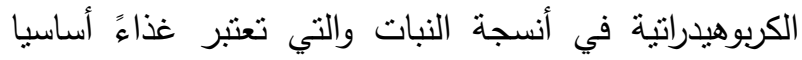
للإنسان وعلفا للحيوان (11)، وقد بدأ في السنوات الأخيرة

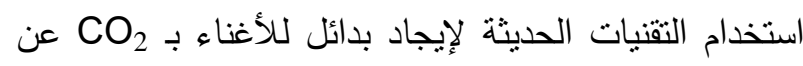

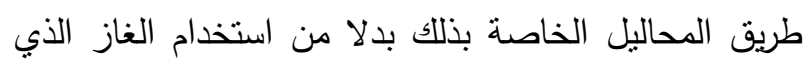
كان قد اقتصر سابقا على الزراعة المحمية إذ أمكن للزراعة

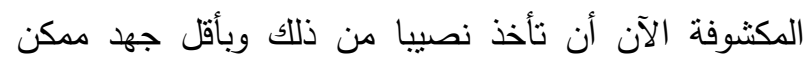

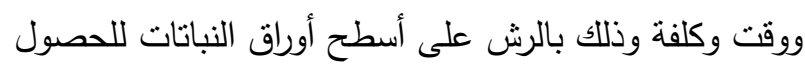
على أفضل نتائج في معظم مؤشرات النمو والإتتاج (18).

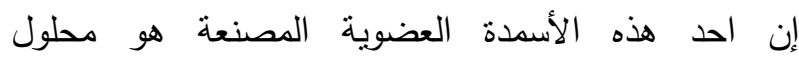
الكاربوليزر والذي يعمل على إمداد النبات بثنائي اوكسيد

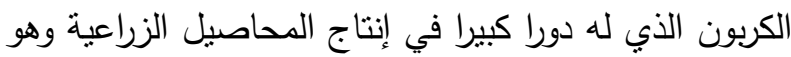

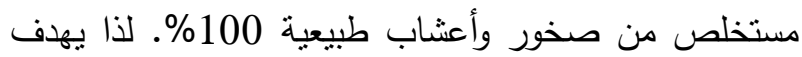
البحث إلى زيادة انتاج وتحسين نوعية بذور اللوبيا من خلال المقدمة المذكورة لدور البورون و ثثائي اوكسيد الكربون.

\section{المواد وطرائق العمل}

نفذ البحث في حقول الخضر في قسم البستتة وهندسة

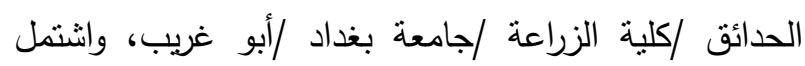
البحث موسمي زراعة ربيعي وصيفي للعام 2014 وذللك لدراسة استجابة نبات اللوبيا للرش الورقي بعنصر البورون

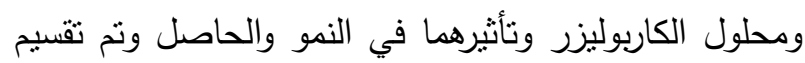
الحقل على شكل مروز بطول 5م والمسافة بين مرز وآخر 0.75 م، إذ اشتملت الوحدة التجريبية على ثلاثة مروز زرعت بذور اللوبيا بتاريخ 28 / 3 | 3 | 2014 و 20 / 6 | 6 | 2014 للموسمين بالتتابع، زرع الصنف مamshorn والمستورد من شركة سما الأوراد لعام 2013 وبصلاحية لمدة عامين على جهة واحدة من المرز و المسافة بين نبات وآخر 0.25 وبلغ عدد النباتات في الوحدة التجريبية 60 نبات وبلغت مساحة الوحدة التجريبية 11.25 م²، تم اخذ عينة عشوائية لنزبة الحقل من مواقع متقرقة وأجريت التحاليل

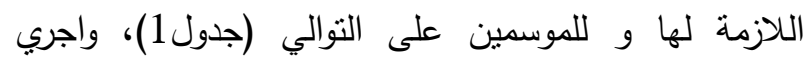
تسميد الحقل بـ 28 كغم.هكتار -1 نتروجين على صورة يوريا و 55 كغ.هكتار -1 فسفور على صورة سوبر فوسفات عند

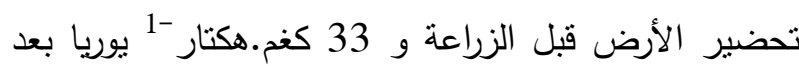

\section{المقدمة}

اللوبيا Vigna unguiculata L.(Walp) هي احد محاصيل العائلة البقولية Leguminosea ويعتقد أن إفريقيا الوسطى هو الموطن الأصلي للوبيا وتتنشر زراعتها في

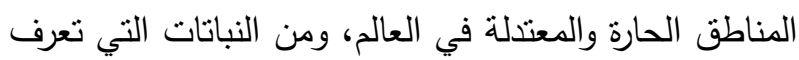
بتحملها للظروف البيئية الحارة والجافة علاوة على تحملها للملوحة وكغيرها من المحاصيل البقولية تساعد على تحسين

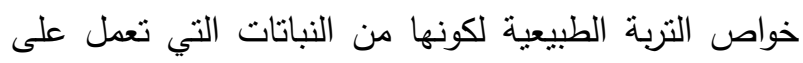

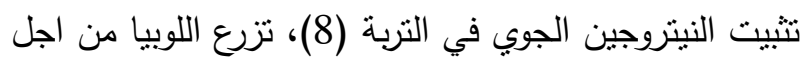

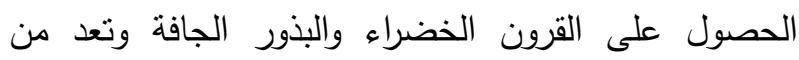
المحاصيل الغنية بالمواد الغذائية إذ يحتوي كل 100 غم من ولندور

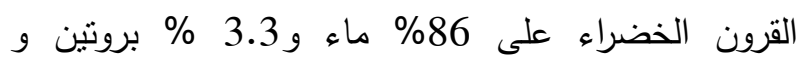

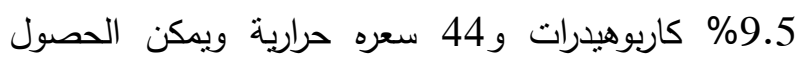
عليها خضراء طازجة أو مطبوخة ومحفوظة بعلب وبطرق مختلفة (9). تُعد البذور الرابط الوراثي الأساسي الذي يحافظ أنط

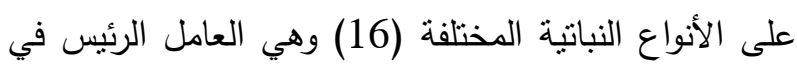

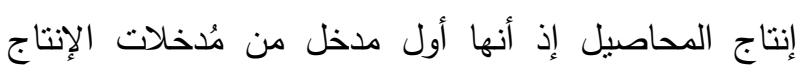
الزراعي وان نوعيتها الجيدة نساهم وحدها في زيادة الإنتاج بنسبة 10 - 15\% (22). تُساهم المغذيات في تجهيز النبات بالعناصر الغذائية وتحسين الحالة التغذوية إذ أثشارت الدراسات الحديثة إن زيادة حاصل العديد من نباتات المحاصيل الزراعية خطيا مع المغذيات الجاهزة للنبات (21). يعد البورون من العناصر الغذائية الضرورية وذو النوانية فعالية كبرى إذ يسهم في تسهيل حركة وانتقال نواتج التمنيل الضوئي من الأوراق إلى مناطق التخزين في النبات ويساهم

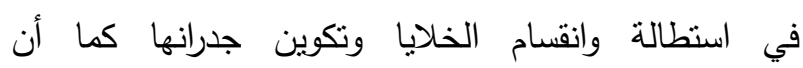
للإخصاب نصيب من فعالية هذا العنصر إذ يثجع إنبات

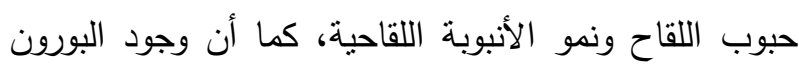
يزيد من مقاومة النبات للجفاف إذ يتحكم في سرعة امتصاص النبات للماء ويعتقد أن له دور كبير في نراكم المحتوى الكربوهيدراتي وزيادة نركيزه في النبات علاوة على تكوينه للأحماض النووية والتي تزيد في بناء البروتين (20). انعكس استخدام الأسمدة العضوية السائلة إيجابا في زيادة لئن نمو وتحسين الإنتاج الزراعي إضافة إلى إسهامها في السي

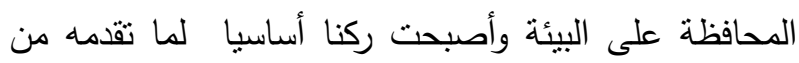
عناصر غذائية مهمة للنبات (4)، فضلا عن الئل الأسمدة 
فكانت تراكيزه 0 0، 1.25، 2.5 سم لنز - ورمز لها

شهر من الإنبات (3)، نم استخدام حامض البوريك 17\% $. \mathrm{C} 2, \mathrm{C} 1$,

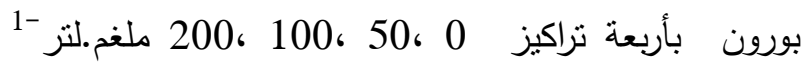

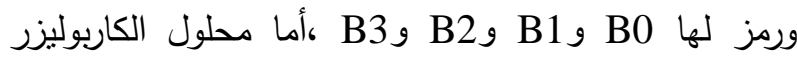

جدول 1. الصفات الكيميائية والفيزيائية للترية للموسمين الربيعي والصيفي لعام 2014

\begin{tabular}{|c|c|c|c|c|c|c|c|c|c|}
\hline النسجة & غم.كفر-1- الغرين & غم.كفي-1- & غم.كفم-1- الرمل & البوتاسيوم & ملغم.كفم-1- الفسفور & النفاهزيزين & 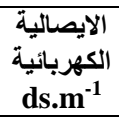 & التربة درجة تفاعل & الصفات \\
\hline طينية غرينية & 432 & 430 & 138 & 275.6 & 23.1 & 25.0 & 2.41 & 7.74 & الموسم الربيعي \\
\hline طينية غرينية & 410 & 420 & 170 & 147 & 15.6 & 30.4 & 2.24 & 7.68 & الموسم الصيفي \\
\hline
\end{tabular}

أجريت التحليلات في مختبرات دائرة التربة والمياه / وزارة العلوم والتكنولوجيا.

جدول 2. يبين مواصفات السماد السائل (الكاريوليزر)

\begin{tabular}{|c|c|c|c|c|c|c|c|}
\hline الكبريت & $\begin{array}{c}\text { الكالسيوم \% } \\
\text { \% }\end{array}$ & $\begin{array}{c}\text { الكاربون الكلي } \\
\text { \% }\end{array}$ & $\begin{array}{c}\text { البوتاسيوم } \\
\text { \% }\end{array}$ & $\begin{array}{l}\text { الفسفور \% } \\
\text { \% }\end{array}$ & $\begin{array}{c}\text { النتروجين } \\
\text { \% }\end{array}$ & pH & الكهربائيل \\
\hline 2 & 4.5 & 20 & 0.34 & $\mathbf{0 . 5 0}$ & 6.6 & 8.6 & 43.4 \\
\hline
\end{tabular}

أجريت التحليلات في مختبرات دائرة التربة والمياه / وزارة العلوم والتكنولوجيا

الظاهري للبذور، ونم حساب الكثافة الظاهرية كما أوردها الخفاجي (1) حسب المعادلة الآثية:

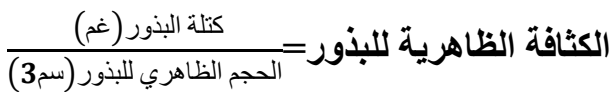
5-الكثافة الحقيقية للبذور م.(سم')-1: نم استخدام حجم معين من كحول الـ xylol في اسطوانة مدرجة من ثم غمر وزن معين من البذور واخذ قراءة تدريج الاسطوانة لتمثل الحجم الفعلي لوزن تلك البذور ثم تحسب الكثافة الحقيقية كما أوردها الخفاجي (1) وفق المعادلة الآتية:

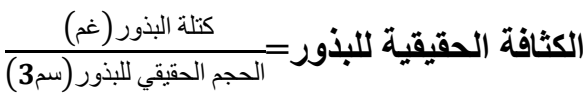
6-النسبة المئوية للكربوهيدرات في البذور: تم تقدير الكربوهيدرات الكلية حسب ما ورد في(5) . 7- النسبة المئوية للبروتين في البذور الجافة: نم تقدير

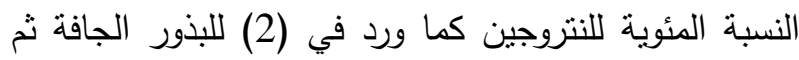
احتساب البروتين على أساس الوزن الجاف وفق المعادلة

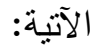
نسبة البروتين على أساس الوزن الجاف = النسبة المئوية 6.25 × للنتروجين في البذور النتائـج والمناقشة 1. تأثير رش البورون وإلكاريوليزر وتداخلاتهما في عدد البذور في القرنة لنباتات اللوبيا للموسمين الربيعي والصيفي :2014 تشير نتائج جدول 3 تفوق المعاملة B3 معنويا بأعلى عدد بذور في القرنة بلغ 9.31 ، 8.86 بذرة.قرنة-1 مقارنة بمعاملة

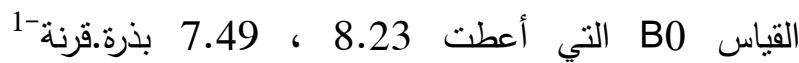

وتم الرش بعد مرور 30، 45، 60 يوم من موسم الزراعة ونفذت كتجربة عاملية وفق تصميم القطاعات الكاملة المعشاة RCBD بثلاثة مكررات واشتنمل كل مكرر على 12 وحدة ولى تجريبية وحللت النتائج وفق البرنامج الإحصائي Genstat L.S.D وقورنت المتوسطات باختبار اقل فرق معنوي وبمستوى احتمال 0.05 (6). وتم قياس الصفات آلاتية : 1-عدد البذور .قرنة-1': تم حساب عدد البذور في القرنات للنباتات الخمس المختارة وثم نم حساب المعدل. 2 -حاصل النبات الواحد من البذور الجافة غم.نبات -1: نم حساب حاصل الوحدة التجريبية التراكمي من البذور الجافة وقسم على عدد النباتات وسجل المعدل. 3- وزن 100 بذرة.غم: تم قياس الوزن بأخذ عينة عشوائية Seed من البذور من كل وحدة تجريبية وعدها بجهاز counter

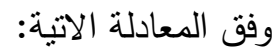

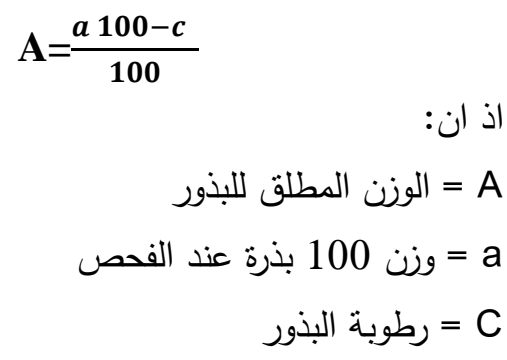
4-الكثافة الظاهرية للبذور غم.(سم) (-1 : : نم حساب الكثافة الظاهرية لكل معاملة من خلال وضع 100 غم في اسطوانة فارغة مدرجة حجمها لتر ودقق سطح استواء البذور داخلها ومن ثم تسجيل قراءة تدريج الاسطوانة والذي يمثل الحجم 
جدول 4. تأثير رش البورون والكاريوليزر وتداخلاتهما في حاصل النبات الواحد من البذور الجافة للموسمين الريبعي

\section{والصبفي 2014}

\begin{tabular}{|c|c|c|c|c|c|c|c|c|}
\hline \multicolumn{9}{|c|}{ حاصل النبات الواحد من البذور الجافة غم } \\
\hline \multicolumn{4}{|c|}{ الموسم الصيفي } & \multicolumn{4}{|c|}{ الموسم الربيعي } & \multirow{2}{*}{ المعاملات } \\
\hline المعدل & 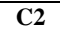 & C1 & C0 & المعلال & C2 & C1 & C0 & \\
\hline 70.0 & 71.0 & 84.0 & 55.0 & 34.6 & 39.4 & 36.1 & 28.2 & B0 \\
\hline 83.7 & 84.2 & 90.7 & 76.2 & 46.2 & 45.1 & 59.7 & 33.8 & B1 \\
\hline 84.2 & 98.7 & 79.1 & 74.7 & 41.9 & 43.2 & 41.9 & 40.7 & B2 \\
\hline \multirow[t]{2}{*}{99.8} & 96.0 & 109.7 & 93.7 & 41.7 & 40.5 & 42.7 & 42.0 & B3 \\
\hline & 87.5 & 90.9 & 74.9 & & 42.0 & 45.1 & 36.2 & المعل \\
\hline & & B & C & & & B & $\mathbf{C}$ & \multirow[b]{2}{*}{ L.S.D } \\
\hline & & 6.2 & 5.3 & & & 4.3 & 3.8 & \\
\hline
\end{tabular}

3. تأثير ش البورون والكاريوليزر وتداخلاتهما في وزن

\section{0 بذرة للموسمين الربيعي والصيفي 2014:}

يتضح من نتائج جدول 5 عدم وجود فروق معنوية لمعاملات البورون ومعاملات الكاربوليزر في وزن 100 بذرة، بينما تفوقت معاملة التداخل B0C2 بأعلى وزن بلغ 20.59 غم

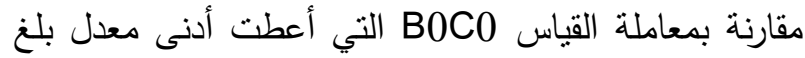
19.38 غم في الموسم الربيعي، وتفوقت المعاملة B1C2 بأعلى معدل بلغ 21.76 غم في الموسم الصيفي مقارنة بالمعاملة B0C1 التي لم تختلف معنويا عن معاملة القياس B0C0 جدول 5. تأثثر رش البورون والكاريوليزر وتداخلاتهما في

وزن 100 بذرة للموسمين الربيعي والصيفي 2014

\begin{tabular}{|c|c|c|c|c|c|c|c|c|}
\hline \multicolumn{9}{|c|}{ وزن 100 بذرة غم } \\
\hline \multicolumn{4}{|c|}{ الموسم الصيفي } & \multicolumn{4}{|c|}{ الموسم الربيعي } & \multirow{2}{*}{ المعاملات } \\
\hline المعدل & $\mathrm{C2}$ & C1 & C0 & المعدل & $\mathrm{C2}$ & C1 & C0 & \\
\hline 20.62 & 20.89 & 20.42 & 20.53 & 19.93 & 20.59 & 19.83 & 19.38 & B0 \\
\hline 21.10 & 21.76 & 21.30 & 20.25 & 19.94 & 19.54 & 20.57 & 19.71 & B1 \\
\hline 21.16 & 21.34 & 21.02 & 21.12 & 20.03 & 19.89 & 19.86 & 20.35 & B2 \\
\hline \multirow{2}{*}{21.26} & 20.82 & 21.62 & 21.31 & 20.02 & 20.09 & 20.00 & 19.97 & B3 \\
\hline & 21.20 & 21.10 & 20.80 & & 20.03 & 20.07 & 19.85 & المعدل \\
\hline \multicolumn{2}{|c|}{ التّاخل } & B & C & & & B & C & \multirow{2}{*}{ L.S.D } \\
\hline \multicolumn{2}{|c|}{1.15} & N.S & N.S & & & N.S & N.S & \\
\hline
\end{tabular}

4.تأثير رش البورون والكاريوليزر وتداخلاتهما في الكثافة

الظاهرية للبذور للموسمين الريبعي والصيفي 2014: تُبين نتائج جدول 6 تفوق المعاملة B2 بأعلى قيمة للكثافة

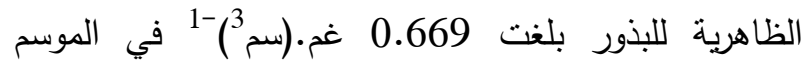
الربيعي، بينما تفوقت المعاملة B3 معنويا بأعلى قيمة بلغت 0.698 غم. (سم 3) -1 والتي لم تختلف معنويا عن المعاملة

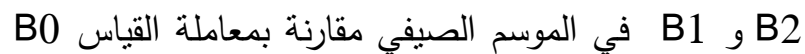

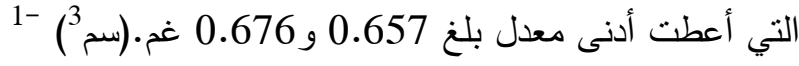

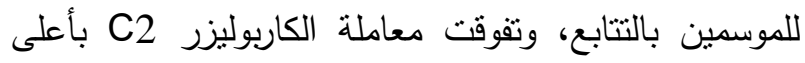
معدل بلغ 0.670 غم. (سم3) -1 في الموسم الربيعي، بينما

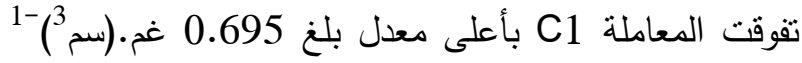

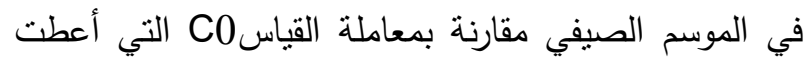

للموعين بالتتابع، وتفوقت المعاملة C1 بأعلى معدل بلغ

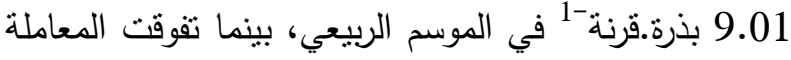
C2 الصيفي مقارنة بمعاملة القياس C0 التي أعطت اقل معدل بلغ 8.49، 7.71 بذرة.قرنة-1 للموسمين بالتتابع، و ت تفوقت معاملة التداخل B1C1 معنويا بأعلى معدل بلغ 9.87 بذرة.قرنة-1 في الموسم الربيعي بينما تفوقت المعاملة Bم3C2 معنويا بأعلى معدل بلغ 9.27 بذرة.قرنة-1 في الموسم

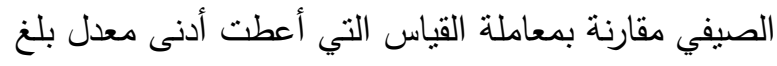
8.03 ، 6.98 بذرة.قرنة-1 لكلا الموسمين بالتتابع. جدول 3. تأثير رش البورون والكاريوليزر في عدد البذور في القرنة لنباتات اللوييا للموسمين الربيعي والصيفي

\section{4}

\begin{tabular}{|c|c|c|c|c|c|c|c|c|}
\hline \multicolumn{9}{|c|}{ عدد البذور.قرنة-1 } \\
\hline \multicolumn{4}{|c|}{ الموسم الصيفي } & \multicolumn{4}{|c|}{ الموسم الربيعي } & المعاملات \\
\hline المعدل & C2 & C1 & CO & المعدل & $\mathrm{C2}$ & C1 & Co & \\
\hline 7.49 & 7.19 & 8.29 & 6.98 & 8.23 & 8.53 & 8.13 & 8.03 & B0 \\
\hline 8.19 & 8.85 & 8.07 & 7.65 & 8.84 & 8.60 & 9.87 & 8.07 & B1 \\
\hline 8.24 & 9.17 & 8.07 & 7.47 & 8.87 & 8.93 & 8.73 & 8.93 & B2 \\
\hline \multirow[t]{2}{*}{8.86} & 9.27 & 8.57 & 8.74 & 9.31 & 9.67 & 9.32 & 8.93 & B3 \\
\hline & 8.62 & 8.25 & 7.71 & & 8.93 & 9.01 & 8.49 & المعدل \\
\hline \multicolumn{2}{|c|}{ التداخل } & B & $\mathrm{C}$ & \multicolumn{2}{|c|}{ التـاخل } & B & C & \\
\hline \multicolumn{2}{|c|}{0.89} & 0.52 & 0.45 & \multicolumn{2}{|c|}{0.73} & 0.42 & 0.37 & L.S.D \\
\hline
\end{tabular}

2. تأثير رش البورون والكاريوليزر وتداخلاتهما في حاصل النبات الواحد من البذور الجافة للموسمين الريبعي والصيفي :2014 تبين نتائج جدول 4 تفوق المعاملة B1 معنويا بأعلى حاصل للبذور الجافة للنبات الواحد بلغ 46.2 غم.نبات فئرول للموسم الربيعي في حين تفوقت المعاملة B3 بأعلى معدل

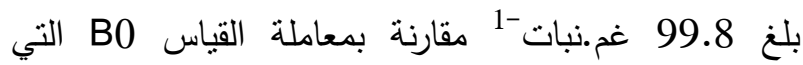
أعطت أدنى معدل بلغ 34.6 و 70.0 غم.نبات -1 للموسمين

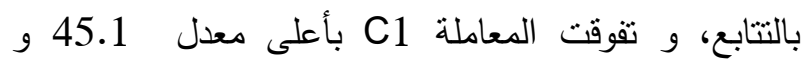
90.9

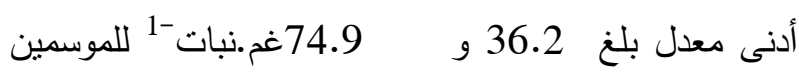
بالتتابع، وتقوقت معاملة التداخل B1C1 بأعلى معدل بلغ

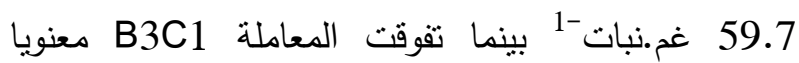
بأعلى معدل بلغ 109.7 غم.نبات -1 في الموسم الصيفي مقارنة بمعاملة القياس B0C0 التي أعطت أدنى معدل بلغ 28.2 و 55.0 غم.نبات -1 للموسمين بالتتابع. 
6. تأثير ش البورون والكاريوليزر وتداخلاتهما في النسبة المئوية للكريوهيدرات في البذور الجافة للموسمين الربيعي والصيفي 2014:

يُلاحظ من نتائج جدول 8 تفوق معاملة البورون B1 بأعلى نسبة كربوهيدرات في البذور الجافة بلغت 64.52 ، 46.57 كناتج 46

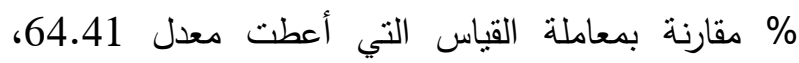
64.41 \% للموسمين بالتتابع، ولم يُلاحظ فروقات معنوية

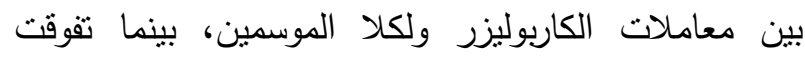
معاملة التداخل B1C0 بأعلى معدل بلغ معاملت 64.70 ، 64.80 \% مقارنة بمعاملة القياس التي أعطت أدنى معدل بلغ بلغ بلغ 64.23 ، 64.33 \% للموسمين بالتتابع. جدول 8. تأثير رش البورون والكاريوليزر وتداخلاتهما في باليع النسبة المئوية للكريوهيدرات في البذور الجافة

للموسمين الربيعي والصيفي 2014.

\begin{tabular}{|c|c|c|c|c|c|c|c|c|}
\hline \multicolumn{9}{|c|}{ النسبة المئوية للكربو هيلرات في البذور الجافة } \\
\hline \multicolumn{4}{|c|}{ الموسم الصيفي } & \multicolumn{4}{|c|}{ الموسم الربيعي } & \multirow{2}{*}{ المعاملات } \\
\hline 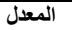 & C2 & C1 & C0 & المعدل & $\mathrm{C} 2$ & C1 & C0 & \\
\hline 64.41 & 64.50 & 64.40 & 64.33 & 64.41 & 64.50 & 64.50 & 64.23 & B0 \\
\hline 64.57 & 64.40 & 64.50 & 64.80 & 64.52 & 64.37 & 64.50 & 64.70 & B1 \\
\hline 64.44 & 64.37 & 64.37 & 64.60 & 64.37 & 64.20 & 64.47 & 64.43 & B2 \\
\hline \multirow{2}{*}{64.42} & 64.40 & 64.37 & 64.50 & 64.37 & 64.37 & 64.33 & 64.42 & B3 \\
\hline & 64.41 & 64.41 & 64.56 & & 64.36 & 64.45 & 64.45 & المعدل \\
\hline \multicolumn{2}{|c|}{ التذاخل } & B & $\mathbf{C}$ & & & B & $\mathbf{C}$ & \multirow{2}{*}{ L.S.D } \\
\hline \multicolumn{2}{|c|}{0.24} & 0.14 & N.S & & & 0.12 & N.S & \\
\hline
\end{tabular}

7. تأثير رش البورون والكاريوليزر وتداخلاتهما في النسبة المئوية للبروتين في البذور الجافة لنباتات اللوبيا للموسمين

\section{الربيعي والصيفي 2014:}

يُلاحظ من نتائج جدول 9 تفوق معاملة البورون B2 معنيفي

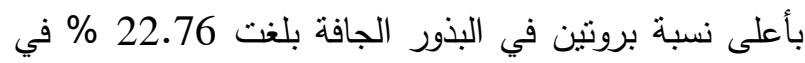

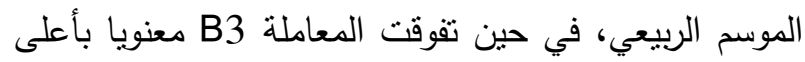
معدل بلغ 22.56\% في الموسم الصيفي مقارنة بمعاملة القياس B0 التي أعطت أدنى معدل بلغ 22.63 و22.39\% للموسمين بالتتابع، وتقوقت معاملة الكاربوليزر

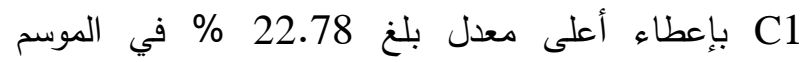
الربيعي، في حين تقوقت المعاملة C2 معنويا بإعطاء أعلى بلى معدل بلغ 22.64\% في الموسم الصيفي مقارنة بمعاملة القياس C0 التي أعطت أدنى معدل بلغ 22.55 و 22.20 ألموسمين بالتتابع، وتقوقت معاملة التداخل B2C2 بإعطاء أعلى معدل بلغ 22.97\% في الموسم الربيعي، في حين تفوقت المعاملة B3C2 بإعطاء أعلى بلى معدل بلغ 22.73\% في الموسم الصيفي مقارنة بمعاملة
معدل بلغ 0.655 و 0.68غم.(سم') -1 للموسمين بالتتابع، في حين تقوقت معاملة التداخل B3C2 و B2C2 و B2C1

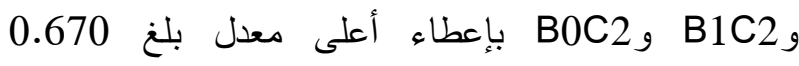
غم.(سم) 3-1 مقارنة بالمعاملة B1C0 التي لم تختلف معنويا عن معاملة القياس B0C0 التي أعطت معدل بلغ 0.653 غم.(سم'3)-1 في الموسم الربيعي، بينما تفوقت المعاملة B3C1 بإعطاء أعلى معدل بلغ 0.703 غم.(سم 3) -1 مقارنة

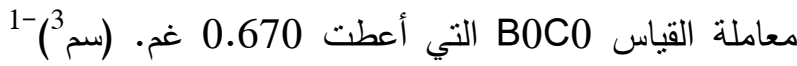
في الموسم الصيفي. جدول 6. تأثير ش البورئ البورن والكاريوليزر وتداخلاتهما في الكثافة الظاهرية للبذور للموسمين الربيعي والصيفي

\section{4}

\begin{tabular}{|c|c|c|c|c|c|c|c|c|}
\hline \multicolumn{9}{|c|}{ الكثافة الظاهرية للبذور غم. (سمج)-1 } \\
\hline \multicolumn{4}{|c|}{ الموسم الصيفي } & \multicolumn{4}{|c|}{ الموسم الربيعي } & \multirow{2}{*}{ المعاملات } \\
\hline المعدل & C2 & C1 & C0 & المعدل & C2 & C1 & C0 & \\
\hline 0.676 & 0.681 & 0.678 & 0.670 & 0.657 & 0.670 & 0.647 & 0.653 & B0 \\
\hline 0.691 & 0.690 & 0.700 & 0.683 & 0.660 & 0.670 & 0.660 & 0.650 & B1 \\
\hline 0.696 & 0.696 & 0.700 & 0.691 & 0.669 & 0.670 & 0.670 & 0.667 & B2 \\
\hline \multirow[t]{2}{*}{0.698} & 0.701 & 0.703 & 0.689 & 0.657 & 0.670 & 0.650 & 0.650 & B3 \\
\hline & 0.692 & 0.695 & 0.683 & & 0.670 & 0.657 & 0.655 & المعدل \\
\hline \multicolumn{2}{|c|}{ 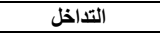 } & $\mathbf{B}$ & $\mathbf{C}$ & \multicolumn{2}{|c|}{ 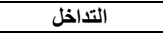 } & B & $\mathbf{C}$ & \multirow{2}{*}{ L.S.D } \\
\hline \multicolumn{2}{|c|}{0.025} & 0.014 & 0.012 & \multicolumn{2}{|c|}{0.010} & 0.006 & 0.005 & \\
\hline
\end{tabular}

5. تأثير رش البورون والكاريوليزر وتداخلاتهما في الكثافة الحقيقية للبذور للموسمين الريبعي والصيفي 2014: تبين نتائج جدول 7 تفوق معاملة البورون B3 بأعلى قيمة

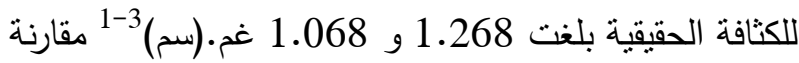
بمعاملة القياس التي أعطت أدنى معدل بلغ

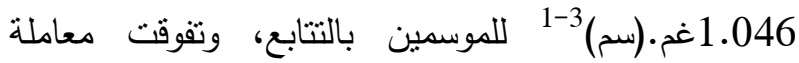
الكاربوليزر C2 بأعلى معدل بلغ

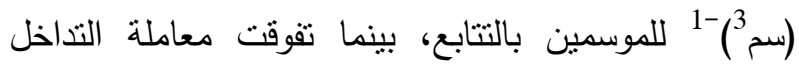

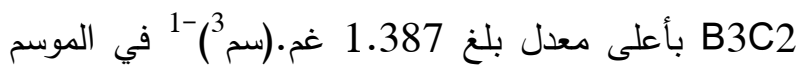
الربيعي، في حين تفوقت المعاملة B1C2 بإعطاء أعلى معدل بلغ 1.081غم.(سم)-1 في الموسم الصيفي مقارنة بمعاملة القياس B0C0 التي أعطت معدل بلغ 1.000 ، 1.048 جدول 7. تأثير رش البورون وإلكاريوليزر وتداخلاتهما في بالئن الكثافة الحقيقية للبذور للموسمين الربيعي والصيفي 2014

\begin{tabular}{|c|c|c|c|c|c|c|c|c|}
\hline \multicolumn{9}{|c|}{ الكثافة الحقيقية للبذور غر. (سع3) } \\
\hline \multicolumn{4}{|c|}{ الموسم الصيفي } & \multicolumn{4}{|c|}{ الموسم الربيعي } & \multirow{2}{*}{ المعاملات } \\
\hline المعدل - (المعل & C2 & C1 & $\mathrm{CO}$ & المعدل - (المعال & C2 & C1 & C0 & \\
\hline 1.046 & 1.048 & 1.042 & 1.048 & 1.056 & 1.167 & 1.000 & 1.000 & B0 \\
\hline 1.067 & 1.081 & 1.072 & 1.048 & 1.179 & 1.203 & 1.167 & 1.167 & B1 \\
\hline 1.054 & 1.053 & 1.058 & 1.051 & 1.222 & 1.167 & 1.250 & 1.250 & B2 \\
\hline \multirow[t]{2}{*}{1.068} & 1.078 & 1.079 & 1.047 & 1.268 & 1.387 & 1.167 & 1.250 & B3 \\
\hline & 1.065 & 1.063 & 1.049 & & 1.231 & 1.146 & 1.167 & المعدل \\
\hline \multicolumn{2}{|c|}{ التذاخل } & B & $\mathrm{C}$ & \multicolumn{2}{|c|}{ التداخل } & B & $\mathrm{C}$ & \multirow{2}{*}{ L.S.D } \\
\hline \multicolumn{2}{|c|}{0.028} & 0.016 & 0.014 & \multicolumn{2}{|c|}{0.153} & 0.088 & 0.076 & \\
\hline
\end{tabular}


النتروجين الجوي بالتربة والتي تزيد من مستويات النتروجين في النبات، فضلا عن دوره المهم في زيادة كفاءة عملية نرين التمثيل الغذائي والتي تزيد من التراكم الكربوهيدراتي في النبات ومن ثم الحصول على كمية اكبر من النتروجين المثبت لقاء

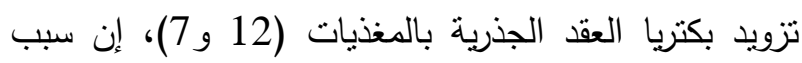
انخفاض نسبة الكربوهيدرات في البذور في بـات معاملات الكاربوليزر ربما يعود إلى دوره في تقليل كمية الماء المفقودة بعملية النتح مما أدى إلى زيادته في الخلية ومن ثم التخفيف دورديف

\section{REFERENCE}

لمكونات الخلية (11) - (11).

1.Al-khafaji, K. M. K. 2009. Seed Technology. The Ministry of Higher Education and Scientific Research. Baghdad University. College of Agriculture. Iraq.

2.Al-Sahaf, F. H. 1989. Applied plant nutrition. Baghdad University. The Ministry of Higher Education and Scientific Research.pp: 209-217.

3.Al-Sahaf, F.H. ; M.Z.K. Al Mharib and A.H. Mahmood. 2012. Response Of Cowpea To Application Methods And Cobalt Concentration. The Iraqi Journal of Agricultural Sciences, 43(6): 53-58.

4.Deore, G. B. . S.Limaye, B. M. Shinde ;and S. L. Laware. 2010. Effect of novel organic liquid fertilizer on growth and yield in chilli (Capsicum annum L.) Asian J. Exp. Biol. Sci. Spl. 1: 15-19.

5.Dubois, M.; , .K. A. Gilles; , J.K. Hamilton; P.A. Rebers. and F. Smith. 1956. Anal. Chem., 26, p. 350.

6.Elsahookie, M.M. and K.M. Wuhaib .1990. Applications On Design And Analysis Of Experiments. The Ministry of Higher Education and Scientific Research. Baghdad University. Iraq.p: 277-300.

7.Favarin, J. L. and J.P. Marini. 2000. Importance of micronutrients for grain production In: National Society of Agriculture, available in: www.sna.com.br.

8.Food and Agriculture Organization (FAO). 2012. Grassland species index. Vigna unguiculata http:// www.fao. Org /ag/ AGP/ AGPC/ doc/Gbase/ data/ pf 000090 .htm accessed 6 Jun.

9.Hassan, A. A. 1997. Fundamental of Vegetables Physiology with Showing Some Problems Deal with Production Physiological
القياس B0C0 التي أعطت أدنى معدل بلغ 22.37 و22.04\% للموسمين بالتتابع. جدول 9. تأثير رش البورون والكاريوليزر وتداخلاتهما في بالي النسبة المئوية للبروتين في البذور الجافة لنباتات اللويبيا

للموسمين الربيعي والصيفي 2014

\begin{tabular}{|c|c|c|c|c|c|c|c|c|}
\hline \multicolumn{9}{|c|}{ النسبة المئوية للبروتين في البذور الجافة } \\
\hline \multicolumn{4}{|c|}{ الموسم الصيفي } & \multicolumn{4}{|c|}{ الموسم الربيعي } & \multirow{2}{*}{ 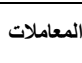 } \\
\hline المعدل & $\mathrm{C2}$ & C1 & Co & 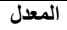 & C2 & C1 & Co & \\
\hline 22.39 & 22.66 & 22.46 & 22.04 & 22.63 & 22.70 & 22.83 & 22.37 & B0 \\
\hline 22.39 & 22.52 & 22.49 & 22.17 & 22.67 & 22.67 & 22.77 & 22.57 & B1 \\
\hline 22.47 & 22.63 & 22.52 & 22.25 & 22.76 & 22.97 & 22.77 & 22.53 & B2 \\
\hline \multirow[t]{2}{*}{22.56} & 22.73 & 22.59 & 22.34 & 22.73 & 22.73 & 22.73 & 22.73 & B3 \\
\hline & 22.64 & 22.52 & 22.20 & & 22.77 & 22.78 & 22.55 & المعدل \\
\hline \multicolumn{2}{|c|}{ التداخل } & B & $\mathrm{C}$ & \multicolumn{2}{|c|}{ التـاخل } & B & $\mathrm{C}$ & \multirow{2}{*}{ L.S.D } \\
\hline \multicolumn{2}{|c|}{0.02} & 0.02 & 0.02 & \multicolumn{2}{|c|}{0.16} & 0.09 & 0.08 & \\
\hline
\end{tabular}

قد يُعزى التفوق المعنوي لبعض معاملات البورون في حاصل نباتات اللوبيا إلى دور البورون المهم في عمليتي التلقيح والإخصاب ودوره المشجع في نمو الأنبوبة اللقاحية ومساهمته في الفعاليات الفسيولوجية كامتصاص الماء والمغذيات وفي لهي نقل الكربوهيدرات المصنعة في الأوراق بعطية البناء الضوئي

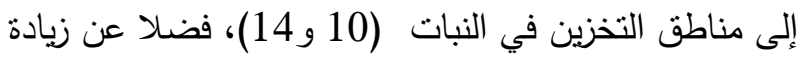
حيوية الأجزاء الأنثوية بتوافر البورون ودوره الايجابي في إنبات حبوب اللقاح وتكوين الأنبوبة اللقاحية ومن ثم زيادة عدد البذور في القرنة مما ينعكس إيجابا في زيادة إنتاج

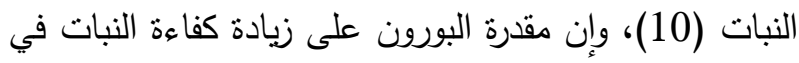

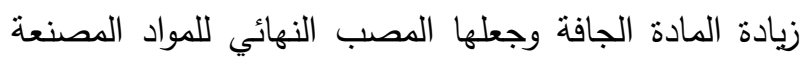
مما يؤثز بشكل ايجابي على إنتاج النبات بزيادة عدد البذور في القرنة أو تكوين بذور ممتلئة مما ينعكس بشكل أو بآخر التراج

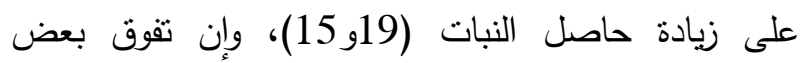
معاملات الكاربوليزر ربما تعود إلى زيادة نركيز قد تكون أدت إلى زيادة نشاط عملية البناء الضوئي والتي لتئي تؤثر في صفات النمو الخضري من خلال زيادة في تراكم

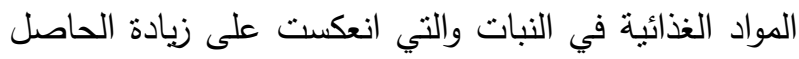
(13). كما إن في إغناء النباتات بـ CO إنتاج الكربوهيدرات والتي تُعد الناتج النهائي لعملية التمثيل الكربوني ودور البورون في تتشيط فعاليات النبات في نقل

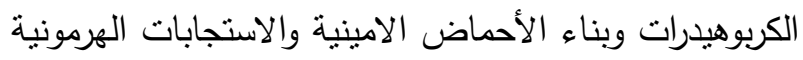
فضلا عن عمله المهم في خزن الطاقة في النبات وسلامة تركيبه (17 21). وان إمداد النبات بـ CO نشاط عملية التمثيل الكربوني وزيادة نواتجه مما يساهم في زيادة الحاصل (12) فضلا عن إن الإغناء بـ CO على تشجيع تكوين العقد الجذرية التي تعمل على تنبيت 
and Some Methods to Minimizeits Effects . Academic Bookshope. Egypt. P: 293-298. 10.Huang, L.; J. Pants; B. Dell and R.W. Bell. 2000. Effect of Boron deficiency on another development and floret fertility in Wheat ( Triticum aestivum L. "Wilgoyne" ). Ann. Bot. 85:493-500.

11. Idso, C. D. 2013. The Positive Externalities of Carbon Dioxide :Estimating the Monetary Benefits of Rising Atmospheric $\mathrm{CO}_{2}$ Concentrations on Global Food Producation. Center for the Study of Carbon Dioxide and Global Change. www. CO2 science.org. p: 5.

12.Nasser, R.R.; M.P. Fuller and A.J. Jellings. 2008. Effect of elevated $\mathrm{CO}_{2}$ and nitrogen level on lentil growth and nodulation .Agronomy for Sustainable Development. Volume 28, Issue 2 ,pp 175-180.

13.Neeraja, G. and B.C. Reddy. 2005. Effect of growth promoters on growth and yield of tomato c.v. Marutham. J. R.es. ANGRAU. 33(3). 68-70.

14.Nachtigall, G. R., and A. R. Dechen. 2006. Micronutrients. In: Ffernandes. M. S.Mineral nutrition of plants.Vicoza: Brazil. Soc. Soil Sci. 13:328-352.

15.Pradeep, M.D. and S. Elamathi. 2007. Effect of foliar application of DAP, micronutrients and NAA on growth and yield of greengram ( Vigna radiate L.). Legum Research. 30 (4) . 305-307.
16.Primala, K.; K. Subramanian; S. M. kannan and K. Vijayalakshmi. 2013. Seed Storage Techniques-Aprimer. Center for Indian knowledge system .Chennai.www.Ciks.Org. 17.Riccardo; L. B.; M. Rieger and S. She-Jean. 1998. A simple, rapid extraction and assay procedure for NAD+dependent sorbitol dehydrogeanase (SDH) in peach. J. Amer. Soc. Hort. Sci. 123(6) 1065-1068 .

18.Salman, A. D.; and S. Q. Sadk. 2014. Influerce Of Foliar application of agrosol and(Ed.) enraizal on the vegetative growth characters and yield quantity of cherry tomato. plant in open field. The Iraqi Journal of Agricultural Sciences -6(4): 32-33

19.Sarhan, I. A. and J. M. A. Aljumaily. 2015. Effect of cycocel and foliar nutrition of nitrogen and boron on growth of soybean cultivars. The Iraqi Journal of Agricultural Sciences - 46(2): 120-135.

20.Shaaban, M. M. 2010. Role of boron in plant nutrition and humanhealth. American J. Plant Physiol. 5(5): 224-240.

21.Taiz, L. and E. Zeiger. 2010. Physiology. $5^{\text {th. }}$ Edition Sinauer Associates, Inc. Publisher Sunderland, Massachusetts-AHS. U. A. pp: 107-117.

22.Vendreleyden, J. 2003. Bean. (phaseolus spp.) - model food legumes. Plant and Soil 252:55-128. 